\title{
Human anatomy in the generation Z's medical studies
}

\begin{abstract}
Each generation of medical students has distinctive attributes that set them apart from previous cohorts. Understanding this generational diversity is paramount for faculty as they search for adequate instructional approaches to mesh with students' learning behaviors. Today's new medical students belong to Generation Z, also known as Centennial generation. They are those born around the early 2000s at the same time as the explosive world-wide spread of mobile devices and social media. The Generation Z's medical students have diverse approaches to dealing with human anatomy and so they have different learning experiences resulting in differences in the kind and amount of their grasp of human anatomy. In those circumstances, it should be no surprise that a combination of methods for learning human anatomy gives the best results.
\end{abstract}

Keywords: generation Z, human anatomy, medical education, medical students
Volume 7 Issue I - 2020

\author{
Rafael Romero-Reveron ${ }^{1,2}$ \\ 'Department of Human Anatomy, Universidad Central de \\ Venezuela, Venezuela \\ ${ }^{2}$ Medical doctor Specialist in Orthopedic Trauma Surgery at \\ Centro Médico Docente La Trinidad,Venezuela \\ Correspondence: Rafael Romero-Reveron, Department of \\ Human Anatomy, Universidad Central de Venezuela, Medical \\ doctor Specialist in Orthopedic Trauma Surgery at Centro \\ Medico Docente La Trinidad, Venezuela \\ Email rafa1636@yahoo.es
}

Received: January 09, 2020 | Published: February 03, 2020

\section{Introduction}

Today's new medical students belong to Generation Z, also known as Centennial generation, Founders, Plurals and others. They are those born mostly between 1995 and 2010, at the same time as the explosive world-wide spread of mobile devices and social media. ${ }^{1}$

Each generation of medical students has distinctive attributes that set them apart from previous cohorts. Understanding the generational diversity is paramount for faculty as they search for adequate instructional approaches to mesh with students' learning behaviors. The Generation Z's medical students have diverse approaches to dealing with human anatomy and so they have different learning experiences resulting in differences in the kind and amount of their grasp of human anatomy. In those circumstances, a combination of methods for learning human anatomy gives the best results. ${ }^{2,3}$

\section{Human anatomy studies in the generation Z's medical studies}

Human anatomy education is foundational to medical studies and, as for previous generations, is a rite of passage for Generation Z's medical students but unlike previous generations, human-anatomy learning methods have evolved from traditional teaching methods of human anatomical dissection, lectures, prosection anatomical models, and tutorials: they are now supplemented by the recently emerging e-learning grounded in web-based technology. Human anatomy studies are indispensable for understanding classifications and interrelationships of different parts of human body, improvement of physicians' manual dexterity and practical skills, three-dimensional perspectives of structures, tactile perception, and the explanation of problems encountered in medicine and surgery and also for improving physicians' expertise in physical examinations, which cannot be carried out correctly without a thorough knowledge of gross and topographical human anatomy. ${ }^{4}$

Generation $\mathrm{Z}$ is the first generation to grow up in a world of widespread access to computers, the internet, mobile devices smartphones, and social media and, as a result, are hyper-connected, confident with technology, and choose self-study using electronic resources in preference to traditional teaching methods.
Generation Z's medical studies also prefer more hands-on experience and on-the-job learning, as well as the aforementioned customized feedback. While they do not want lecture and prefer doing over memorizing. Their preferred communication method is texting, Twitter, Whatsapp and others.

Tools based on evolving technologies for improving Generation Z's students' learning of human anatomy, are being actively sought and evaluated. ${ }^{2,3,6}$ Some searchers confirm surgeons' ongoing concern about diminished learning and knowledge of human anatomy among junior physicians and this could significantly bolster the case for emphasizing the importance of keeping intense human anatomy studies. $^{7-9}$

\section{Discussion}

Human-anatomy learning methods have evolved from traditional teaching methods to emerging e-learning grounded in web-based technology. Generation $\mathrm{Z}$ is the first generation to grow up hyperconnected, confident with technology, and choose self-learn using electronic resources in preference to traditional teaching methods. Generation Z's students prefer a development and comforting environment that includes frequent feedback, delivered supportively, to help them build skills and confidence.

Since competent physicians need a deep understanding of human anatomy for safe clinical and surgical procedures the advantages of integrating human anatomy learning and imaging are improved clinical application of human anatomy and an increase in Generation Z's medical student's interest in human anatomy. Faculty should build up strategies to transform approach the anatomical education landscape in response to the ingrained traits of the incoming Generation $\mathrm{Z}$ medical students.

\section{Conclusion}

Generation $\mathrm{Z}$ medical students have diverse e-learning approaches to dealing with human anatomy and so they have different learning experiences. In line with this approach, Today's the human anatomy learning has to be complemented by the use of electronic resources in teaching Generation Z. Faculty should be willing to develop strategies 
to transform the anatomical education landscape in response to the ingrained traits of the incoming Generation $Z$ students. The emergence of Generation Z-associated educational issues requires significant faculty time and creativity on an ongoing basis.

\section{Acknowledgments}

None.

\section{Conflicts of interest}

The authors declare there are no conflicts of interest.

\section{References}

1. Plochocki JH. Several Ways Generation Z May Shape the Medical School Landscape. J Med Educ Curric Dev. 2019.

2. Barmaki R, Yu K, Pearlman R, et al. Enhancement of anatomical education using augmented reality: an empirical study of body painting. Anat Sci Edu. 2019;12(6):599-609.

3. Bork F, Stratmann L, Enssle S, et al. The benefits of an augmented reality magic mirror system for integrated radiology teaching in gross anatomy. Anat Sci Edu. 2019;12(6):585-598.
4. Vorstenbosch M, Kooloo I, Bolhuis S, et al. An investigation of anatomical competence in junior medical doctors. Anat Sci Educ. 2016;9(1):8-17.

5. Boysen P, Daste L, Northern T. Multigenerational challenges and the future of graduate medical education. Ochsner J. 2016;16(1):101-107.

6. Ruzycki SM, Desy JR, Lachman N, et al. Medical education for millennials: How anatomists are doing it right. Clin Anat. 2019;32(1):20-25.

7. Dissabandara LO, Nirthanan SN, Khoo TK, et al. Role of cadaveric dissections in modern medical curricula: a study on student perceptions. Anat Cell Biol. 2015;48(3):205-212.

8. Sheikh A, Barry D, Gutierrez H, et al. Cadaveric anatomy in the future of medical education: What is the surgeons view?. Anat Sci Educ. 2016;9(2):203-208

9. Romero-Reverón R. Venezuelan surgeons' ongoing concern. Anat Cell Biol. 2017;50(1):12-16. 